\title{
A Guarneri violin in the attic: the power of dendrochronology for analysing musical instruments
}

\author{
Mauro Bernabei ${ }^{*}$ (I)
}

\begin{abstract}
Dendrochronology is the science that dates wooden artefacts by measuring annual growth rings visible in the wood. And, in the case of musical instruments, the method is non-invasive. In addition, dendrochronology can also help to identify the wood's provenance and to supply information on how the soundboard was made, giving details of ring width and regularity. This study also demonstrates the effectiveness of dendrochronology in attributing a musical instrument to an important luthier. It deals with a privately owned violin, whose date and origin had previously remained uncertain, despite various attempts to authenticate, at least, its technical and stylistic characteristics. The outermost tree-ring of the instrument's soundboard was dendrochronologically dated to the year 1696 and attributed, with certainty, to the Italian luthier Giuseppe Guarneri filius Andreae, father of the famous Bartolomeo Giuseppe Guarneri "del Gesù". Thanks to dendrochronology, in this way, a twin of an already existing violin has been identified that was made by the same luthier. Both violins are identical in construction, having the same veining and dimensions, and the wood from the same tree was used in all parts, including the soundboard. Dendrochronology has, thus, been proven to be an extremely useful method, which has transformed a violin of uncertain value into a museum piece.
\end{abstract}

Keywords: Dendrochronology, Attribution, Musical instrument, Guarneri, Violin, Dating

\section{Introduction}

Dendrochronology is a wood-dating technique, based on measuring the growth rings of trees [1] that has found its ideal application in dating musical instruments [2]. In bowed string instruments, the soundboard, which is the front that characterises the instrument's sound, is most often made of Norway spruce (Picea abies Karst.), a "resonance wood" that is easily dated dendrochronologically [3]. In most cases, the wood traditionally used by the greatest luthiers came from well-defined locations, famous for this use, and generally limited to the central Eastern Alps, with small isolated pockets also in Central Europe [4]. In the Alps, the best-known locations range

*Correspondence: mauro.bernabei@ibe.cnr.it

CNR-IBE, Institute for BioEconomy, National Research Council, via Biasi 75, 38010 SanMichele all'Adige, Trento, Italy from the Trentino to Carnia, to Cadore (Friuli Venezia Giulia) and to Slovenia [5]. Other well-known areas, especially for non-Italian luthiers, are the Bavarian forests, Tyrol and some parts of Switzerland (Obersaxen, for example). Further sites are located in Eastern Europe, including some woodlands in Poland, Romania and southern Russia [6].

Generally, the wood selected by luthiers follows strict specifications: it must be without imperfections like knots, reaction wood or fibrous anomalies, and it generally comes from high-altitude woodlands.

In synthesis, the most important aspects in the dendrochronological study of musical instruments are:

1 the species, Norway spruce, which is perfectly suited to dendrochronological analyses;

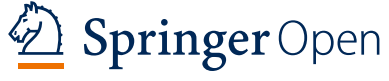

(c) The Author(s) 2021. This article is licensed under a Creative Commons Attribution 4.0 International License, which permits use, sharing, adaptation, distribution and reproduction in any medium or format, as long as you give appropriate credit to the original author(s) and the source, provide a link to the Creative Commons licence, and indicate if changes were made. The images or other third party material in this article are included in the article's Creative Commons licence, unless indicated otherwise in a credit line to the material. If material is not included in the article's Creative Commons licence and your intended use is not permitted by statutory regulation or exceeds the permitted use, you will need to obtain permission directly from the copyright holder. To view a copy of this licence, visit http://creativeco mmons.org/licenses/by/4.0/. The Creative Commons Public Domain Dedication waiver (http://creativecommons.org/publicdomain/ zero/1.0/) applies to the data made available in this article, unless otherwise stated in a credit line to the data. 
2 limited and well-known areas of provenance that facilitate the selection of corresponding reference chronologies;

3 wood that is free of defects, with narrow and regular annual rings typical of high-altitude trees.

All these characteristics lend greater reliability to the dating of musical instruments, when compared with other applications of dendrochronology such as dating the wooden structure of historical buildings, wooden sculptures or panel paintings.

Less well known is the fact that, using dendrochronology, a musical instrument may be attributed to a particular luthier. The logic behind this is that modern luthiers, just like their historical counterparts, carefully consider the characteristics of the timber they use for making their instruments. When choosing the wood for the soundboard, they pay a lot of attention to its acoustic properties, any possible defects and aesthetic considerations. Once they have found the right wood, they will continue to use timber of the same provenance, if possible from the same batch of supply and sometimes even from the same tree.

This is demonstrated in the instruments of many famous luthiers. One of them was Stradivari [7]. Even though it is difficult to date his instruments against already existing reference chronologies - mainly because, as yet, we do not know with certainty, where the wood for Stradivari's instruments came from - the relative dating of his instruments is often correct, and the values of the statistical tests are often significant. Meaning that his instruments date very well one against another, but their absolute dates are sometimes uncertain [8]. For a comparison, the dendrochronological time-series of some of Stradivari's instruments are available on the website of the International Tree-Ring Database: https://www.ncdc. noaa.gov/paleo-search.

Here, the exceptional case of an unknown instrument is presented, which was precisely dated by dendrochronology and attributed to the luthier Giuseppe Guarneri filius Andreae (1666-1740). The aims of this study are:

- to verify the possibility of non-invasive dendrochronological analysis by dating a photograph of the violin that was initially supplied through social media;

- to attribute the instrument to a luthier's school or directly to a luthier; and

- to verify the instrument's dendrochronological dating and its attribution to a luthier by the traditional and generally recognised examination of its style, and by consulting relevant documents, relying on the resources and experience of one of the greatest experts of ancient musical instruments.

\section{Materials and methods}

The violin is inherited and private property. In order to date it dendrochronologically, its annual growth rings were measured on both sides of the soundboard, directly from the images sent by the owner via WhatsApp. In these early photos, the chinrest and tailpiece are still attached to the violin (Fig. 1).

Dendrochronological measurements were taken where the largest number of annual rings could be included, using two techniques:

1 The photos were printed and the rings measured using a LINTAB (LINear TABle, Rinn Tech, Germany), with the software TSAP-Win (Rinn Tech, Germany);

2 The rings were measured digitally, using the CooRecorder program (Cybis, Image Coordinate Recording Program, Sweden).

Then the principal dendrochronological parameters were calculated such as: mean ring width (MV), standard deviation (SD), mean sensitivity (S) and first-degree autocorrelation (A). MV and SD make an instrument unique because they may influence sound quality $[9$, 10]. The standard deviation, in particular, indicates the dispersion of data around the mean and is considered an indication for regular annual growth [11]. Mean sensitivity, S, shows how the tree reacted to environmental changes, whilst first-degree autocorrelation, A, indicates to what extent the formation of one ring depends on the width of the preceding ring [12]. After dating the instrument, $\Delta t$ was calculated, which indicates the difference, in years, between the date shown on the violin's label and

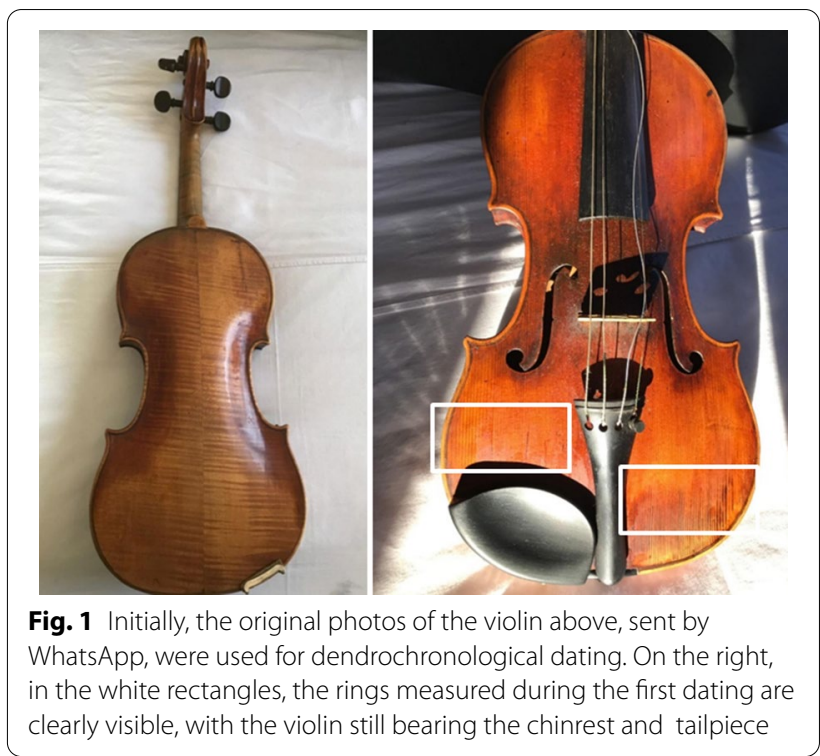


the dendrochronological date [4]. In fact. the value $\Delta t$ refers to the number of growth rings lost in trimming the soundboard and on account of seasoning the wood.

The tree-ring series were visualised by PAST4 and TSAP-Win software that was also used for statistical tests. Considering the variability of $t$-values in different kinds of software, and in order to keep the results homogeneous, the values calculated by the PAST4 program were adopted.

\section{Results}

\section{The instrument}

The violin's soundboard was made in the traditional way, which means that it consists of two identical parts of wood that derive from the same tree, with the direction of growth pointing inwards. Hence, the most recent annual rings are at the centre of the instrument. The violin's body is $35.55 \mathrm{~cm}$ long, $16.65 \mathrm{~cm}$ wide at the top and $20.25 \mathrm{~cm}$ wide at the lower end. Its dendrochronological parameters are given in Table 1.

Table 1 The dendrochronological parameters of the soundboard

\begin{tabular}{ll}
\hline No. of rings & 82 \\
$\Delta \mathrm{t}$ (years) & 9 \\
$\mathrm{MV}(0.01 \mathrm{~mm})$ & 118.2 \\
$\max .(0.01 \mathrm{~mm})$ & 232.8 \\
$\min .(0.01 \mathrm{~mm})$ & 56.4 \\
$\mathrm{SD}$ & 44.6 \\
$\mathrm{AC}$ & 0.86 \\
MS & 17 \\
\hline The number of rings represents the maximum number of annual growth rings \\
measured in continuation on the instrument's soundboard. $\Delta$ t is the difference \\
between the date written on the label and dendrochronological dating. MV is \\
the mean ring width (incl. maximum and minimum). SD is standard deviation. \\
AC is first-degree autocorrelation. MS is mean sensitivity
\end{tabular}

\section{Dating}

The results of both dating techniques are analogous and have produced two time-series, one for each half of the soundboard, both consisting of 81 tree-rings, whose dating, however, differs by one year. After having checked their correlation, the two single curves resulted in a mean chronology containing 82 annual rings. This chronology was then compared statistically and visually with 129 reference chronologies [13] and 187 time-series of different, individual musical instruments $[4,5]$.

As a result, the violin's last ring dates to 1694. After having removed the tailpiece, the dating was extended to 1696 . The highest correlation values (Table 2) were obtained in comparison with the mean CNR-IBE laboratory chronology (MI03, so far unpublished), then with the reference chronology of Paneveggio [13] (Fig. 2) and with the mean chronology of the instruments from the Cherubini Collection in Florence [4]. The year 1696 is, therefore, a terminus post quem, to which the number of rings that were lost during the preparation of the soundboard and, possibly, some years for seasoning the wood must be added.

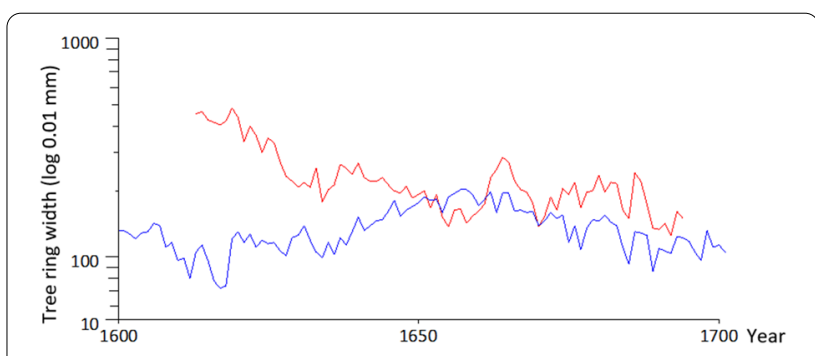

Fig. 2 Comparison between the violin's dendrochronological series (in red) and the Paneveggio Chronology (Bernabei \& Bontadi 2011). TBP 5.19, THO 5.53, Glk 67.10***

Table 2 The statistical tests refer to the year 1694 (based on the first dendrochronological measurement taken from the photo sent via social media)

\begin{tabular}{lllll}
\hline Reference chronologies & Region & $\mathbf{T}_{\text {BP }}$ & $\mathbf{T}_{\text {HO }}$ & $\mathbf{G l k}$ \\
\hline MI03 (unpublished) & Various & 5.73 & 7.00 & $68.90^{* * *}$ \\
Bernabei and Bontadi (2011) & Paneveggio (Italy) & 5.19 & 5.53 & $67.10^{* * *}$ \\
AMC01 (Bernabei et al., 2010) & Master of Accademia & 5.02 & 6.07 & $70.70^{* * *}$ \\
Bernabei et al. (2018) & Trentino (Italy) & 4.46 & 4.73 & $64.60^{* *}$ \\
MST (Bernabei et al., 2017) & Master of Museum of Trieste & 3.45 & 3.23 & 3.73 \\
svit169 & Simmenthal (Switzerland) & 3.65 & 3.16 & $68.30^{* * *}$ \\
Kerner & Ötztal & 3.08 & 3.98 & $62.80^{*}$ \\
ital022 & Tuscany (Italy) & 2.35 & 2.92 & $61.60^{*}$ \\
svit173 & Obersaxen (Switzerland) & 2.39 & $63.40^{* *}$ \\
\hline
\end{tabular}

Overlap: 82 rings. TBP: Student's t-test adapted from Baillie and Pilcher; THO: Student's $t$-test adapted from Hollstein; Glk: Gleichläufigkeit, represents the percentage of agreement between the growth sign (+ or - ) from 1 year to the next; ${ }^{*}$, **, and ${ }^{* * *}$ : statistical significance of Glk at confidence levels $95.0 \%, 99.0 \%$ and $99.9 \%$ 


\section{Attribution to a luthier}

The year 1696 for the fabrication of the violin corresponds exactly to the golden age of violin-making in Italy [14]. This has provoked curiosity and has led to investigations to find out as much as possible about the instrument, including its label.

It is customary for violins to bear a label on the inside that gives the luthier's name, the place where it was made and, sometimes, further information. The originality of labels is often questioned for various reasons. In the past many labels have been substituted. One reason being that prior to photography and during the period where a photograph was not yet economically feasible, many violinmakers, collectors and restorers collected original labels. The original was removed from the instrument and a replica label was inserted in its place. Entire notebooks of original labels were created and some are housed in museums. Those who were more respectful of history would simply make a tracing so as to leave the original undisturbed inside the instrument. In any case, an archive of label information was important even before the advent of photography. Count Cozio di Salabue had a collection of original labels, mostly of Cremonese origin, now housed in the National Music Museum of Vermillion South Dakota (USA). Some replacement labels were carefully executed while others demonstrate a lack of knowledge as to how the original was printed.

Sometimes, the original writing was simply copied, perhaps adding a spelling mistake; at other times, however, it was changed-a little or very much. Occasionally, the instruments made by some good apprentice were labelled with the name of the workshop owner, who was much better known, which automatically increased the instrument's value. More often, however, substituting the original label with that of a famous luthier was only the first step towards counterfeiting. In the light of these considerations, it is generally not recommended to rely on a musical instrument's label for dating it or attributing it to a possible luthier.

In this particular case, the label (Fig. 3) bears the writing "Joseph Guanerius Filuis Andreae Cremonae Sub Titulo S. Theresie, 1705", that is, "Giuseppe Guarneri, son of Andrea (note the error Filuis instead of Filius), in the name of Saint Theresa (made it) in the year 1705". The last number of the year, previously mistaken for an " 0 ", might be a " 5 " or a " 6 ".

Considering the dendrochronological dating to the year 1696, and adding a certain number of rings that were lost during the preparation of the soundboard, plus a few years for the possible seasoning of the wood, the date shown on the label would seem perfectly compatible.

However, this does not necessarily mean that the violin was made by the famous luthier. In order to prove

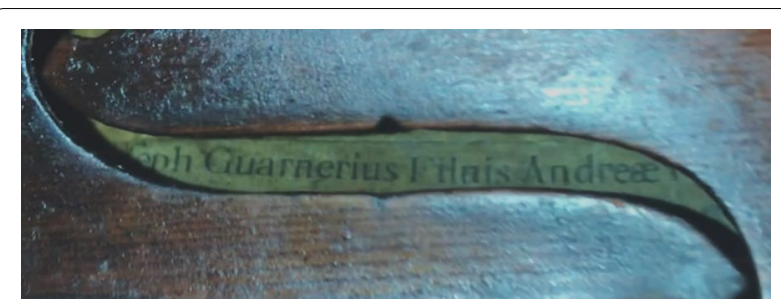

Fig. 3 The writing on the label as seen through the f-holes. It reads "Joseph Guarnerius Filuis Andreae Cremonae Sub Titulo S. Theresie, 1705", where the two final digits would appear to have been added later

the attribution, the dendrochronological time-series of the violin analysed had to be compared with that of a violin definitely made by Giuseppe Guarneri.

In fact, as mentioned in the introduction, once a luthier had found the right wood, he tended to use wood of the same provenance, sometimes even of the same tree, for various instruments. But where might one find the dendrochronological time-series of violins that had definitely been made by Giuseppe Guarneri?

The first search was made on the Internet. After countless pieces of information of all kinds that were nearly always misleading, a dendrochronological report by Peter Ratcliff [15] was found https://vichyenche res.files.wordpress.com/2014/10/125-violon-josephguarnerius-dendrochronologie.pdf that had been prepared for the prestigious French auction house Vichy Enchères (Vichy, France) that specialises in antique musical instruments. The report deals with the dendrochronological analysis of a violin by Giuseppe Guarneri. Peter Ratcliff is a highly esteemed luthier and dendrochronologist, and the auction house is reputable and well-recognised, which makes the publication reliable, too. Unfortunately, the dendrochronological dating was not mentioned in the paper but there was a photograph of the violin on the cover. Immediately, the time-series taken from the WhatsApp photo was compared with a time-series taken from the cover of the report. The result is shown in Fig. 4.

After some initial incredulity, considering that the two curves are almost perfectly superimposable on each other $\left(\mathrm{T}_{\mathrm{BP}} 8.12, \mathrm{~T}_{\mathrm{HO}} 9.45\right.$, Glk $\left.71.90^{* * * *}\right)$, it became clear that the two violins are most likely made using wood from the same tree, indicating the real possibility of a second violin by the same maker (see Additional file 1). At this point, in order to confirm the attribution and to dispel any doubt, it was necessary to verify the dendrochronological results by a technical and 


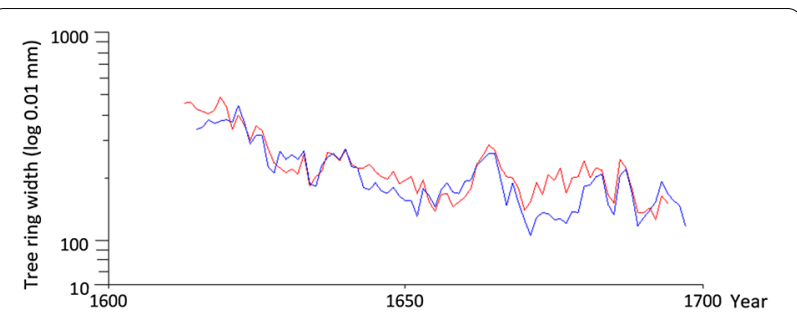

Fig. 4 Comparison between the violin's series from this study (in red) and the series taken from an instrument that has been attributed with certainty to Joseph Guarneri. Dendrochronological Report by Peter Ratcliff for the auction house Vichy Enchères (Vichy, France). TBP 8.12, THO 9.45, Glk 71.90***

stylistic examination, carried out by an expert of classical stringed instruments.

\section{Technical and stylistic characteristics}

The technical and stylistic examination of the instrument was carried out by Bruce Carlson. Carlson is one of the world's greatest experts of classical violins. He was also a member of the Scientific Committee for the exhibition "Masterpieces of Antonio Stradivari" on the occasion of the 250th anniversary of Stradivari's death. Even more importantly, Carlson is also a specialist of other violins made by the Guarneri family. He has been a member of the Scientific Committee of an exhibition of Giuseppe's son, Bartolomeo Giuseppe Guarneri "del Gesù's" violins, for which he also prepared the catalogue [16].

The violin's technical and stylistic examination has actually confirmed its attribution to Giuseppe Giovanni Battista Guarneri of Cremona. During an endoscopic examination, several signs of restorations from the distant past came to light, at which time the original label was probably replaced by the present one. On the inside of the violin, the signature, in ink, of Nicolò Bianchi 1861 is still visible. Bianchi was an Italian luthier, then working in Paris, and he must have carried out one of these restorations. Finally, on the inside of the instrument, a coat-ofarms that seems to belong to the important noble family of the Spinolas from Genoa is impressed in red sealing wax, indicating that they probably owned the violin at some time.

Bruce Carlson then compared the violin with another violin, attributed with certainty to Giuseppe Guarneri, which is kept in his studio. By chance, this particular violin turned out to be the one from the auction house Vichy Enchères, whose dendrochronological time-series had already been obtained from the photo on the cover of Peter Ratcliff's report. In this way, it was possible to compare the time-series of both violins directly and to confirm their analogies.
This direct comparison of the two instruments yielded another surprise. It was established that this was one of those rare cases where two violins are considered twins, which means that they are identical with regard to the choice of timber, having the same veining and the same design on the soundboard, the ribs and at the back (Fig. 5). The two violins are also identical as far as their construction, dimensions and varnish are concerned. Peter Ratcliff had dated the other violin to the year 1695, and it is believed to have been made in 1705 , which is identical to the year just about legible on the label of the violin examined in this paper (Fig. 3).

\section{Discussion}

\section{Technical data}

The value $\Delta \mathrm{t}$ (Table 1), i.e. the difference between the year noted on the label and the dendrochronological date, which is nine years for our violin, indicates that very few annual rings were lost during the working of the soundboard and that the wood used arrives almost up to the bark. An estimated $5 \mathrm{~mm}$ of wood was eliminated under the bark. In fact, considering that the average ring width towards the end of growth is $0.86 \mathrm{~mm}$, the outer part of wood cut off can be at most $7.7 \mathrm{~mm}$ (average ring width $0.86 \mathrm{~mm} \times 9 \Delta \mathrm{t}$ ). It is, therefore, likely that, including a few years for wood seasoning, the margin cut off is about $5 \mathrm{~mm}$.

This would also suggest that the wood from which the soundboard has been made was seasoned only for a very short time. Subtracting at least seven or eight annual rings for working the wood, the time for wood seasoning is reduced to only 1 or 2 years, which is considered sufficient for the wood's good acoustic quality [17].

The remaining dendrochronological parameters (Table 1) are in line with those typical of classical violinmaking $[4,5]$ and indicate that ring width, their uniformity and the absence of any defects are the most important characteristics taken into consideration by luthiers when they choose their timber.

\section{The provenance of the Norway spruce wood}

From the correlation coefficients with numerous Norway spruce reference chronologies valid for dating musical instruments [13], the most significant values (Table 2) have come up with chronologies from musical instruments (MI03, AMC01) and with those from the Province of Trento [18]. The lowest, or sometimes even totally absent, correlation values have been obtained with the chronologies of Bavaria, Switzerland and other regions famous for the production of resonance wood (Table 2). It can, therefore, be affirmed that the timber from which 


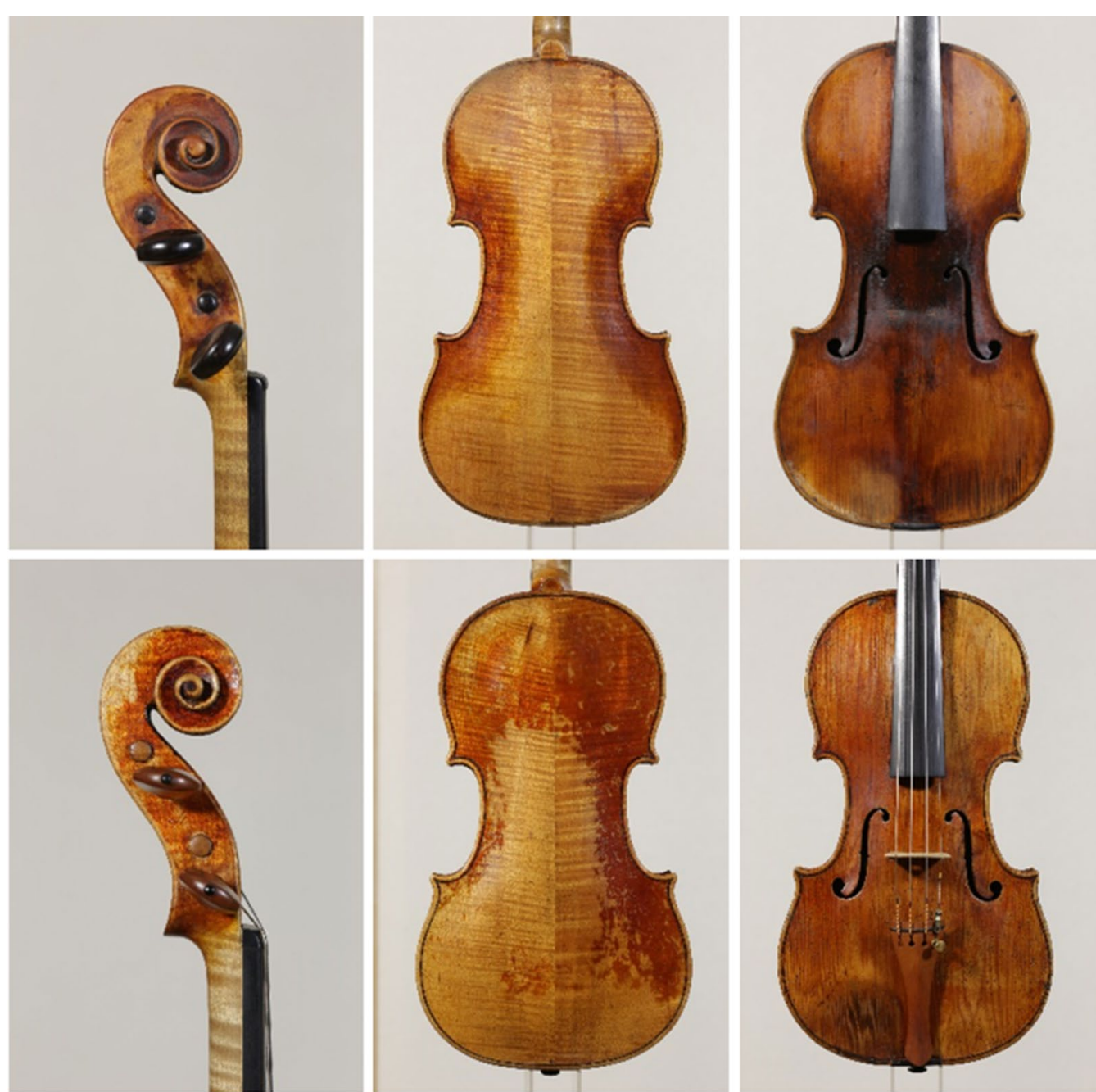

Fig. 5 Comparing two violins. Above, without chinrest and tailpiece, the violin from this study. Below, the instrument P. Ratcliff refers to in his Dendrochronological Report

the violin's soundboard was made derives from the Eastern Alps, from an area fairly close to the forest of Paneveggio, in Trentino.

\section{Dating and attribution}

Dendrochronological dating unequivocally confirms the violin's most recent annual growth ring as the year 1696. This year is compatible with the luthier's name on the label (Fig. 3). Furthermore, a comparison with timeseries taken from a violin that previously had been attributed to Giuseppe Guarneri with certainty, shows the analogous course of the two dendrochronological curves (Fig. 4). Finally, a notable expert has confirmed the attribution on technical and stylistic grounds. The attribution can, therefore, be considered certain.

Giuseppe Giovanni Battista Guarneri, known as filius Andreae, that is, son of Andrea, was the second son of Andrea Guarneri and also his apprentice (hence, filius Andreae in the signature). He was born in Cremona on 25 November, 1666, and worked with his father until, in 1698, he inherited the workshop [19]. His style of making violins was inspired by Stradivari, and is of excellent quality. There is no known violin of his with an original label that precedes the year 1720. Guarneri died in Cremona around 1740 [20]. His youngest son, Bartolomeo Giuseppe (1698-1744), became one of the greatest luthiers ever and, because he incorporated the nomen sacrum I.H.S. on his instrument labels, he became known as Giuseppe Guarneri "del Gesù" [21].

Finally, a comparison of the violin examined in this study, with the violin sold at the auction house Vichy Enchères that had been securely attributed to Giuseppe Guarneri previously, has shown that the two instruments are twins. 
In the past, twin violins made by great luthiers were more common than one might expect. In case of the Guarneri family, the famous violin named "Cannone" that was made by the above-mentioned Giuseppe Guarneri "del Gesù" and played by Paganini, has a twin called "Carrodus". Both are very similar throughout, and the soundboards have been made from wood of the same tree [22]. There is only a slight difference in age between them: Cannone dates to 1742 and Carrodus to 1743 .

Another two violins made by Giuseppe Guarneri "del Gesù", considered twins, are the "Goldberg-Baron Vitta", once owned by the violinist and conductor Szymon Goldberg, and "Kreisler", belonging to the famous violinist Fritz Kreisler. Both instruments are now kept in the Library of Congress in Washington, DC. The two violins are compared on the Library's website, and their characteristics are given https://www.loc.gov/item/ihas.20015 4418/. Both instruments were made in the same year, probably in 1730 .

Apart from these famous violins, there are many other twins, and sometimes up to three identical instruments, like the ones that were made by the luthier Lorenzo Storioni. Some violins are twins only in part, where, for example, the soundboards derive from the same tree but some characteristics differ such as the wood at the back, of the ribs and the shape of the scroll.

There were many reasons for making two or three identical instruments. As mentioned above, a violin's acoustics were one of its most important characteristics, and that depended on particular technical and stylistic solutions and on the right timber. Occasionally, when an instrument's qualities were particularly appreciated by the luthier, the musician who bought it or by the audience, the inclination was to make an identical violin, using the same varnish, technique, and especially the same timber.

Aesthetics also played an important role for luthiers [23], for example when using maple wood with splendid veining at the back or with Norway spruce wood with indented rings [24] that make pleasant ornaments on the instrument's soundboard.

Sometimes, there would be a special demand for identical instruments from particular kinds of ensembles such as quartets or for chamber music. Furthermore, twin violins were made to use up remaining timber or in order to improve an instrument's characteristics. Whatever the reason, coming across twin violins, made by a famous luthier of the past, constitutes a discovery within the discovery and makes the violin recently found even more special (see Additional file 1).

\section{Conclusions}

Before this study, neither the violin's date nor its attribution were known with certainty. The dendrochronological analysis of a WhatsApp photo (!) placed this musical instrument into a particular historical period, the age of classical violins, giving rise to hypotheses regarding the timber's provenance and the violin's possible attribution. Afterwards, further technical and stylistic analyses confirmed the early results: the violin was made by the luthier Giuseppe Guarneri, filius Andreae, probably in the year 1705-as would appear from its label-but in any case after the definite terminus post quem in 1696. Finally, a twin violin was found that had been made by the same famous luthier at the same time and from the same timber, which further increases the rarity of the two musical instruments. The study presented in this article demonstrates the power of dendrochronological research, which has transformed an unknown violin from the attic into a precious museum piece.

\section{Supplementary Information}

The online version contains supplementary material available at https://doi. org/10.1186/s40494-021-00521-4.

Additional file1: Tree-ring data in Tucson format.

Acknowledgements

The author would like to thank Bruce Carlson for his comments, suggestions and for the inspiring conversations we had. The author also wishes to express his gratitude to Dr. Christa Backmeroff, without whom this study would not have been intelligible.

Authors' contributions

The author read and approved the final manuscript.

Funding

This research was not supported by any public funding.

Availability of data and materials

The datasets used and/or analysed during the current study are available from the corresponding author on reasonable request.

\section{Declarations}

Competing interests

The author declares to have no competing interests.

Received: 27 February 2021 Accepted: 16 April 2021

Published online: 14 May 2021

References

1. Baillie MGL. Tree-ring dating and archaeology. London: The University of Chicago Press Ltd; 1982.

2. Bernabei M, Čufar K. Methods of Dendrochronology for Musical Instruments. In: Pérez MA, Marconi E (ed) Wooden musical instruments. Different forms of knowledge. Book of end of WoodMusICK COST action FP1302. Cité de la Musique; 2018. p. 67-80.

3. Schweingruber FH. Trees and wood in dendrochronology. New York: Springer; 1993. p. 402. 
4. Bernabei M, Bontadi J, Rossi RG. A dendrochronological investigation of stringed instruments from the collection of the Cherubini Conservatory in Florence, Italy. J Archaeol Sci. 2010;37:192-200.

5. Bernabei M, Bontadi J, Čufar K, Baici A. Dendrochronological investigation of the bowed string instruments at the Theatre Museum Carlo Schmidl in Trieste. J Cult Herit. 2017;27S:S55-62.

6. Corona E. Caratterizzazione dendrocronologica degli strumenti liutari. Legno Cellulosa Carta. 1998;1:16-20.

7. Topham J, McCormick D. A Dendrochronological Investigation of Stringed Instruments of the Cremonese School (1666-1757) including "The Messiah" violin attributed to Antonio Stradivari. J Archaeol Sci. 2000;27:183-92.

8. Grissino-Mayer HD, Sheppard PR, Cleaveland MK, Cherubini P, Ratcliff $P$, Topham J. Adverse implications of misdating in dendrochronology: addressing the re-dating of the "Messiah" violin. Dendrochronologia. 2010;28(3):149-59.

9. Ille R. Eigenschaften und Verarbeitung von Fichtenresonanzholz für Meistergeigen (II). Holztechnologie. 1976;17:32-5.

10. Bariska M. Zur Geschichte der Holzverwendung beim Musikinstrumentenbau. Schweiz Z Forstwes. 1996;147(9):683-93.

11. Bucur V. Acoustics of wood. 2nd ed. Berlin: Springer; 2006.

12. Kaennel M, Schweingruber FH. Multilingual glossary of dendrochronology. Berne: Birmensdorf Haupt Pub; 1995. (WSL/FNP).

13. Bernabei $\mathrm{M}$, Bontadi J. Determining the resonance wood provenance of stringed instruments from the Cherubini Conservatory Collection in Florence, Italy. J Cult Herit. 2011;12(2):196-204.

14. Hart G. The Violin: its famous makers and their imitators. E-Book No. 21982. Public domain USA, 2007. http://www.gutenberg.org/ebooks/ 21982. Accessed 04 Apr 2020.

15. Ratcliff P. Tree-ring and dendrochronological analysis of the belly of a violin by Giuseppe Guarneri, known as Giuseppe, Filius Andrea, Cremona, circa 1705. 2014. http://violin-dendrochronology.com/reports.html. Accessed 13 Mar 2019.
16. Beare C, Carlson B, Mosconi A. Joseph Guarnerius "del Gesù". Cremona (ed) NLF. 1995; p. 78.

17. Obataya E, Zeniya N, Endo-Ujiie K. Effects of seasoning on the vibrational properties of wood for the soundboards of string instruments. JASA. 2020;147(2):998-1005.

18. Bernabei M, Bontadi J, Nicolussi K. Observations on Holocene subfossil tree remains from high-elevation sites in the Italian Alps. Holocene. 2018;28(12):2017-27.

19. Chiesa C, Rosengard D. Guarneri del Gesù — a brief history. In: Biddulph $P($ ed) The violin masterpieces of Guarneri del Gesù, Stinehour Press: Lunenburg. 1994.

20. Giuseppe RC. filius Andreae. Guarneri Strad. 2009;120(1430):56-7.

21. Hill WH, Hill AF, Hill AE. The violin makers of the Guarneri family. New York: Dover Books; 1991. p. 272.

22. Carlson B. The "Cannone" and the original fittings. In: Proceedings of the International Conference on Violin Making Restoration and Conservation of the violin Guarneri 'del Gesù' (1743) known as 'Cannone'. Genova: Thursday October 14, 2004. Civica Biblioteca Berio. Edited by Genoa City Council for Communication and City Promotion; 2004.

23. Bernabei M, Macchioni N, Ricetti VM, Sisto L. A multi-analytical study on the Mango Longo Guitar, a Baroque masterpiece from the Castello Sforzesco, Milan, Italy. J Cult Herit. 2018;34:69-73.

24. Romagnoli M, Bernabei M, Codipietro G. Density variations in spruce wood with indented rings (Picea abies Karst). Holz Roh-Werkstoff. 2003;61(4):311-2

\section{Publisher's Note}

Springer Nature remains neutral with regard to jurisdictional claims in published maps and institutional affiliations.

\section{Submit your manuscript to a SpringerOpen ${ }^{\circ}$ journal and benefit from:}

- Convenient online submission

- Rigorous peer review

- Open access: articles freely available online

- High visibility within the field

- Retaining the copyright to your article

Submit your next manuscript at springeropen.com 